\title{
The authors reply
}

\section{Os autores respondem}

\section{Los autores responden}

\author{
Anita Liberalesso Neri 1 \\ Flávia Silva Arbex Borim 1 \\ Samila Sathler Tavares Batistoni 1 \\ Meire Cachioni 1 \\ Dóris Firmino Rabelo 2 \\ Arlete Portella Fontes 1 \\ Mônica Sanches Yassuda 3
}

doi: 10.1590/0102-311X00087919

Prezadas Editoras,

O caráter acumulativo da ciência e sua ênfase na necessidade de abertura à crítica são características fundamentais do processo de construção do conhecimento. Acreditar na importância desses pressupostos e praticá-los constantemente faz de nós melhores pesquisadores e ajuda-nos a produzir dados válidos. Dessa forma, acolhemos com muita simpatia a Carta ao Editor de Lima et al. 1, contendo comentários sobre o artigo que publicamos em CSP 2.

Nós não só estávamos cientes do valor do trabalho de derivação de evidências de validade de uma versão brasileira da CASP-19, feito pela professora e seus colaboradores, como destacamos o caráter pioneiro da sua publicação. Nossas justificativas para a realização de um novo estudo creditam valor aos procedimentos e aos dados desse trabalho. Ao utilizar amostra composta por adultos e idosos residentes na Região Nordeste, e também nas regiões Sudeste e Sul, nós pretendemos oferecer uma contribuição à compreensão do funcionamento da CASP-19 em diferentes contextos culturais no Brasil.

Nem os fundamentos e nem o conteúdo da escala são uma completa unanimidade na pesquisa internacional, dada a complexidade do construto, com significados fortemente arraigados na cultura. Antes de serem obstáculos, essas características estimulam o investimento nos fundamentos, no conteúdo, na linguagem e no formato do instrumento. Oxalá outros pesquisadores decidam partir dos dados de Lima et al. 1 e de Neri et al. 2, para investigar o comportamento da CASP-19 em outros contextos e em outros segmentos representativos da ampla heterogeneidade das experiências de velhice no país.

Nós igualmente solicitamos a autorização do Dr. Martin Hyde para realizar a validação semântico-cultural da CASP-19. O Professor esclareceu que a escala não é coberta por direitos autorais, e que, sendo de livre acesso, tem seu uso liberado a quaisquer organizações de pesquisa, sem fins lucrativos. Sua resposta foi de encorajamento e confiança em nosso discernimento e em nossa capacidade de realizar o trabalho, sem nenhuma exigência, sugestão ou restrição.

Os cidadãos ingleses aos quais se destinou a escala original tinham nível de escolaridade expressiva e inequivocamente mais alto do que os brasileiros. Para nós, esse fato justifica restringir a priori o uso da CASP-19 a adultos e idosos brasileiros com escolaridade mais alta e testar sistematicamente os efeitos do nível de escolaridade sobre o desempenho da escala nos diversos segmentos da população adulta e idosa do Brasil. Optamos por excluir analfabetos e pessoas com compreensão e expressão
1 Faculdade de Ciências

Médicas, Universidade

Estadual de Campinas,

Campinas, Brasil.

2 Universidade Federal do

Sudoeste da Bahia, Vitória da Conquista, Brasil.

3 Universidade de São Paulo,

São Paulo, Brasil.

\section{Correspondência}

F. S. A. Borim

Faculdade de Ciências

Médicas, Universidade

Estadual de Campinas. Av. Tessalia Vieira de Camargo 126, Campinas, SP 13083-887, Brasil.

flarbex@hotmail.com 
deficientes da linguagem escrita. Além disso, testamos a consistência interna da escala como um todo e de seus fatores em diferentes níveis de escolaridade.

Uma questão adicional sobre o uso da escala no Brasil é que não sabemos se e como o conteúdo e a linguagem da CASP-19 fazem parte do cotidiano de adultos e idosos brasileiros de vários extratos de idade e escolaridade. É mais um argumento em favor da necessidade de investigar mais a fundo as questões de educação, origem cultural e coorte a qual pertencem os respondentes de estudos metodológicos envolvendo a escala.

Sabemos que um dos objetivos da análise fatorial é a redução de dimensões, assim como sabemos que a construção de instrumentos válidos e econômicos é um objetivo muito caro aos psicometristas. Com base nos dados que obtivemos poderíamos ter sugerido que fosse realizada uma diminuição das dimensões ou fatores e do número de itens da CASP. Não o fizemos por julgar que seria uma decisão prematura, considerando o tamanho $(\mathrm{n}=368$ ), a composição (a maioria mulheres; $66,8 \%$ dos participantes com 9 ou mais anos de escolaridade; 8,2\% com 44 a 54 anos, 15,6 \% com 55 a 59 anos, 24,8\% com 60 a 64 anos e 51,8\% com 65 anos e mais; 54,3\% residentes na Região Sudeste, 36,7\% na Nordeste e $9 \%$ na Região Sul), a forma de recrutamento e a origem da amostra (por conveniência, em programas não formais de educação orientados a adultos e idosos socialmente ativos e envolvidos). Os fatores que obtivemos (autorrealização/prazer e controle/autonomia) também merecem mais investigação quanto a seu significado entre falantes da língua portuguesa no Brasil, antes que se façam afirmações e sugestões mais categóricas. Preliminarmente, nossos resultados podem ser descritos como indicativos da validade da CASP-19 para adultos mais velhos e idosos brasileiros com bom nível de escolaridade.

Vistos em conjunto, os dois artigos comentados nestas páginas de CSP poderão funcionar como pontos de partida para a realização de outros estudos metodológicos e para a condução de pesquisas populacionais com a CASP-19. Novos trabalhos deverão investir em análises de validade de construto, por meio de análises fatoriais exploratórias e confirmatórias aplicadas a amostras mais robustas e a diferentes segmentos etários, educacionais, culturais e populacionais, assim como deverão investir em mais estudos de validade convergente. Será bom que esses utilizem instrumentos mais explorados e com tradição de uso mais estabelecida entre adultos e idosos brasileiros do que a CASP-19.

\section{Colaboradores}

A. L. Neri planejou e escreveu a versão do comentário. F. S. A. Borim, S. S. T. Batistoni, M. Cachioni, D. F. Rabelo, A. P. Fontes e M. S. Yassuda realizaram a revisão do comentário.

\section{Informações adicionais}

ORCID: Anita Liberalesso Neri (0000-0002-68337668); Flávia Silva Arbex Borim (0000-00017316-1145); Samila Sathler Tavares Batistoni (0000-0002-8587-8298); Meire Cachioni (00000001-5220-410X); Dóris Firmino Rabelo (00000002-0791-7781); Arlete Portella Fontes (00000001-7829-473X); Monica Sanches Yassuda (00000002-9182-2450).

\section{Referências}

1. Lima F, Patribu K, Laks J, Campos MS. Considerações sobre a CASP-19 no Brasil. Cad Saúde Pública 2019; 35:e00070619.

2. Neri AL, Borim FSA, Batistoni SST, Cachioni M, Rabelo DF, Fontes AP, et al. Nova validação semântico-cultural e estudo psicométrico da CASP-19 em adultos e idosos brasileiros. Cad Saúde Pública 2018; 34:e00181417.

Recebido em 08/Mai/2019

Versão final reapresentada em 17/Mai/2019

Aprovado em 27/Mai/2019 